\title{
DIABETES TOOLKIT TO CREATE A COLLABORATIVE PATHWAY
}

A new toolkit designed to link dental and medical care is being prepared by NHS England. Some details of the toolkit were revealed by Janet Clarke, deputy CDO, at BDIA Dental Showcase last month.

Patients with diabetes should automatically be referred to a dentist as well as other health professionals to check for periodontal disease as a result of the toolkit which is due to be published by early next year. Currently, such a patient is referred to a podiatrist and an optician but not to a dentist, she explained.

Janet said: 'You will know about the link between diabetes and oral health and that link is becoming better known and the evidence is strong.'

'We are also developing a commissioning standard so that commissioners are aware of these issues and can start thinking about commissioning dental services that would be helpful for people with diabetes. We have worked closely on this with Diabetes UK and our diabetes colleagues in NHS England.'

Simon O'Neill, Director of Health

Intelligence at Diabetes UK, said: 'Periodontitis and Type 2 diabetes share the common risk factor of diet, and therefore there's potential for a combined preventative approach.

'Recent evidence has also suggested that improved periodontal outcomes could have a direct effect on Type 2 diabetes outcomes, and vice versa.

'We are pleased to be working with our colleagues at NHS England to raise awareness about the connection between periodontitis and Type 2 diabetes. We would support a clear pathway to dental care for people with Type 2 as already exists for podiatry, for example.'

\section{A UNIVERSAL HEALTHCARE LANGUAGE ON THE WAY \\ An update on digital transformation was \\ included in briefings in both the Innovation \\ Theatre and the CDO zone at the recent BDIA \\ Dental Showcase 2018 event in London. \\ The most significant innovation is likely to be the news that a new terminology is to be introduced across healthcare. SNOMED CT is a universal language which is mandated for use by everyone working in the NHS from April 2020. As it's a coding change, the impact will be on computer management systems and not on clinical practice. \\ Michael Bond, a terminology specialist now working with NHS Digital, outlined briefly the history of disease classification back to the $17^{\text {th }}$ century. In the last few decades the need for accurate healthcare data has driven the need to adopt today's evolved standard. \\ SNOMED CT, the most comprehensive terminology in the world, appears to be here to stay and is already in use in general medical practices, mental health and community services and some hospitals. Based around \\ machine readable coding combined with human readable descriptions, it's an internationally understood reference terminology which will help support patient care, clinical safety, decision support, professional development, service improvement and commissioning processes. \\ 'It will make your medico-legal records less ambiguous and easier to read. It adds more value to your data and has massive implications for public health. At NHS Digital it gives us the ability to look at data and interrogate it.' \\ As an example, he said, 55162003 is a tooth extraction while 245568002 is an UR6 and those codes will be the same whether you work in dentistry or oncology; in the UK, Uruguay or USA. In future, thanks to SNOMED CT, the NHS would be able to understand how many teeth are taken out, which ones they are and why. Michael advised his audience to ensure their computer management system can handle SNOMED CT.}

\section{OCDO ON TOUR@BDIA}

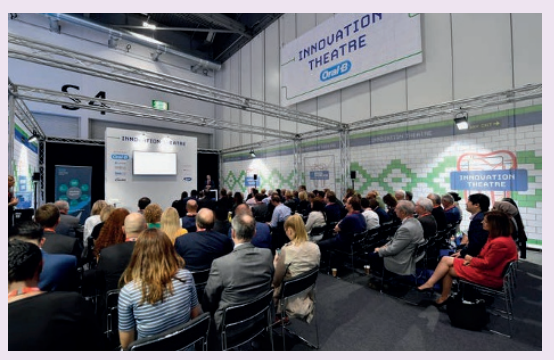

The activities underway in the Office of the Chief Dental Officer (OCDO) reached a wide audience last month as CDO Sara Hurley and her team settled in for a 3 day stint at BDIA Showcase at London's Excel 4 to 6 October.

On each of the three days Sara and her colleagues, including deputies Eric Rooney and Janet Clarke, were in the Innovation Theatre to give a rundown of their work. Otherwise they were to be found in the CDO zone where there were presentations on workforce issues, special projects, digital innovations and clinical updates.

As part of the CDO briefing, Sara gave a presentation called: 'You said, we did.' She set out the work she and her team are undertaking in particular on improving oral health and the launch of Starting Well. She also referenced the Advancing Pathway Dental Care in Education and Training Review, likely to bring about changing responsibilities for team members and the work of the Faculty of General Dental Practice which is also looking at broadening the remit of DCPs.

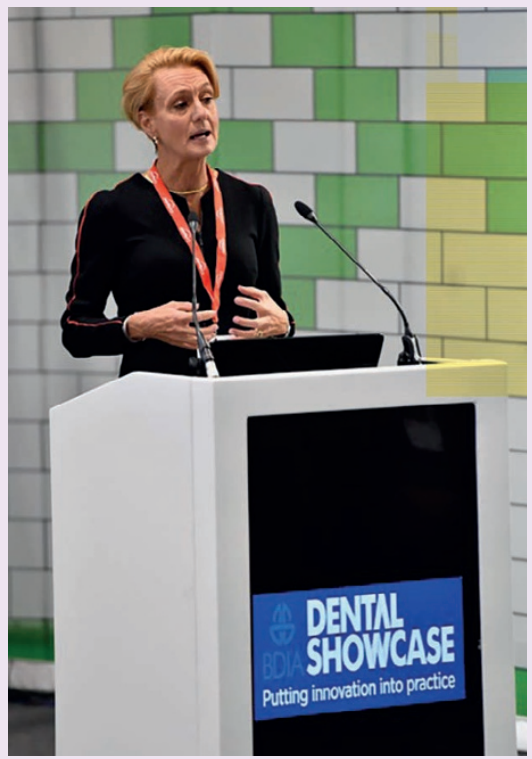

